\title{
The Rho kinase inhibitor fasudil augments the number of functional endothelial progenitor cells in ex vivo cultures
}

\author{
EUNJU O ${ }^{1}$, HYUN-YOUNG AHN ${ }^{2}$, HYUN-KYUNG KIM ${ }^{1}$, JI CHANG YOU ${ }^{3}$, \\ JONG-CHUL SHIN ${ }^{2}$ and YOUNG AE JOE ${ }^{1}$ \\ ${ }^{1}$ Cancer Research Institute and Department of Medical Lifescience, ${ }^{2}$ Department of Obstetrics and \\ Gynecology, Division of Maternal-Fetal Medicine and ${ }^{3}$ Department of Pathology, College \\ of Medicine, The Catholic University of Korea, Seoul, Republic of Korea
}

Received March 15, 2011; Accepted April 13, 2011

DOI: $10.3892 / \mathrm{ijmm} .2011 .698$

\begin{abstract}
Rho kinase (ROCK) has been implicated in the regulation of vascular tone, endothelial dysfunction, inflammation and remodeling. Endothelial progenitor cells (EPC) have been proven to have the efficacy of therapeutic neovascularization in ischemia. However, the scarcity of EPCs limits cell therapy. Using an in vitro EPC culture assay, Y27632 was found to increase the number of adherent EPCs. In this study, we investigated the effect of fasudil, another ROCK inhibitor being used in the clinic, on EPC number and examined whether EPCs expanded by fasudil are functional in vitro and in vivo. In $e x$ vivo cultures of EPCs, fasudil effectively increased the number of ac-LDL/UEA-1 positive cells as well as adherent cells, in contrast to H89, a less selective ROCK inhibitor. Fasudil also increased EPC numbers in culture up to $10 \mu \mathrm{M}$, in a dose-dependent manner. When EPCs expanded with fasudil were examined for the migratory activity toward stromal cell-derived factor-1 and vascular endothelial growth factor, these cells retained functional properties in migration, albeit with some decrease. Fasudil-cultured EPCs labeled with PKH26 showed an activity similar to non-treated EPCs
\end{abstract}

Correspondence to: Dr Young Ae Joe, Cancer Research Institute and Department of Medical Lifescience, College of Medicine, The Catholic University of Korea, Banpo-dong 505, Seocho-gu, Seoul 137-701, Republic of Korea

E-mail: youngjoe@catholic.ac.kr

Abbreviations: BS, Griffonia (Bandeiraea) simplicifolia; BSA, bovine serum albumin; EPC, endothelial progenitor cell; DiI-acLDL, 1,1'-dioctadecyl-3,3,3',3'-tetramethylindocarbocyanine-labeled acetylated low-density lipoprotein; HUVEC, human umbilical vein endothelial cell; KDR, kinase insert domain receptor; LDPI, laser Doppler perfusion imaging; MNC, mononuclear cell; ROCK, Rho kinase; SDF-1, stromal cell-derived factor-1; siRNA, small interfering RNA; UEA-1, Ulex europaeus agglutinin-1; VEGF, vascular endothelial growth factor; vWF, von Willebrand factor

Key words: Rho kinase inhibitor, endothelial progenitor cell, fasudil, ischemia, neovascularization for cellular adhesion into an endothelial cell (EC) monolayer and incorporation into capillary-like structures formed by ECs. Finally, when EPCs cultured with fasudil $\left(10^{6}\right.$ cells/ mouse) were injected into ischemic limbs, these cells showed a blood flow recovery at a level comparable to non-treated control EPCs and increased neovascularization. Therefore, these data suggest that the ROCK inhibitor fasudil can provide a beneficial effect in the treatment of ischemic diseases by increasing EPC numbers.

\section{Introduction}

Substantial evidence suggests that endothelial progenitor cells (EPCs) exist within the total population of mononuclear cells and play a crucial role in neovascularization of ischemic tissue $(1,2)$. Ischemia can trigger the release of bone marrow derived EPCs into the periphery and the mobilized EPCs then contribute to new blood vessel formation (3). Cytokines such as the granulocyte macrophage colony-stimulating factor (GM-CSF), vascular endothelial growth factor (VEGF), and stromal cellderived factor-1 (SDF-1) were reported as potent stimulators of EPC mobilization (3-5). However, the scarcity of EPCs in the bone marrow and in peripheral blood could limit the cell therapy of EPCs. EPC amplification is an important issue in cell therapy. In an attempt to find pharmacological substances that increase EPC number, among various tested inhibitors we identified the Rho kinase (ROCK) inhibitor, Y27632 that exhibited such activity.

The small GTPase Rho, and its downstream effector, ROCK have been implicated in many of the pathogenic processes such as endothelial dysfunction, vasoconstriction, inflammation, cellular migration and proliferation and a procoagulant state (6). At the cellular level, the Rho/ROCK pathway is important in controlling migration, proliferation, differentiation, apoptosis, survival and gene transcription. In endothelial cells, inhibition of Rho/ROCK has been shown to augment the expression and activity of endothelial nitric oxide synthase (eNOS) (7-9), and to improve endothelial function in coronary artery disease patients (10). The inhibition of ROCK has been shown to have a beneficial effect in a variety of cardiovascular disorders including angina, ischemic stroke, ischemia-reperfusion injury and heart failure (11-13). 
Lipid lowering agents such as HMG CoA reductase inhibitors or statins elicit the cholesterol-independent or 'pleiotrophic' effects in part mediated by inhibition of ROCK $(14,15)$. Statins have also been reported to increase of EPC proliferation and mobilization, although not in a ROCK/endothelial nitric oxide (NO) synthesis pathway $(16,17)$. Interestingly, Y27632, a ROCK inhibitor increased EPC number in our in vitro culture condition.

Among the ROCK inhibitors, fasudil has been proven in clinical studies to offer benefits in ischemic stroke and vasoconstriction by inhibiting ROCK (12). Since Y27632 showed a marked effect on the increase of EPC number in our studies, we compared several ROCK inhibitors including fasudil in terms of their ability to enhance the EPC number in ex vivo culture, and investigated whether this increase in the number of EPCs by fasudil is functional and useful for cell therapy.

\section{Materials and methods}

Cell culture. Human umbilical vein endothelial cells (HUVECs) were isolated from human cords as previously described (18), maintained in 20\% FBS (Gibco-BRL, Grand Island, NY), $30 \mu \mathrm{g} / \mathrm{ml}$ endothelial cell growth supplements (Sigma, St. Louis, MO, USA), $90 \mu \mathrm{g} / \mathrm{ml}$ heparin (Sigma) and $1 \%$ antibiotics in M199 (Gibco-BRL), and used at passages 3-8.

For EPC culture, human umbilical cord blood samples were collected in sterile blood bag (Green Cross, Korea) containing heparin as the anticoagulant. Written informed consent was obtained from all mothers and all procedures were approved by the Institutional Review Board at The Catholic University of Korea, College of Medicine (approval no. CUMC10U901). Our study conformed to the principles outlined in the Declaration of Helsinki for use of human tissue or subjects. Mononuclear cells (MNCs) were isolated from the cord blood sample by a Ficoll-Paque Premium (density of $1.077 \mathrm{~g} / \mathrm{ml}$; GE Healthcare, NY, USA) density gradient centrifugation method as previously described (19). Isolated MNCs $\left(2,500 / \mathrm{mm}^{2}\right)$ were seeded on culture dishes coated with $20 \mu \mathrm{g} / \mathrm{ml}$ fibronectin (FN) and maintained in the HUVEC medium. After 3 days, non-adherent cells were removed by washing with PBS and adherent cells were further cultivated until day 5-7.

Characterization of differentiated adherent EPCs. To characterize the cells as having features of cells of the endothelial lineage, we examined the adherent cells for their ability to uptake of 1,1'-dioctadecyl-3,3,3',3'-tetramethylindocarbocyanine-labeled acetylated low-density lipoprotein (DiI-acLDL) (Invitrogen, Eugene, Oregon) and to bind to Ulex europaeus agglutinin-1 (UEA-1, Sigma) as previously described (19).

Fluorescence activated cell sorting (FACS) analysis was performed for the assessment of other endothelial cell marker expression of EPCs cultured in the presence or absence of fasudil for 6 days. The cultured cells were isolated from culture plates by incubating with $1 \mathrm{mM}$ EDTA ( $\mathrm{pH}$ 7.4) in PBS for 3-5 min at $37^{\circ} \mathrm{C}$, and $\mathrm{Fc}$ receptors and nonspecific binding of immunoglobulin were blocked by human $\operatorname{IgG}$ (Sigma) treatment. The cells $\left(2 \times 10^{5}\right)$ were then incubated at $4^{\circ} \mathrm{C}$ for $30 \mathrm{~min}$ in the dark with phycoerythrin (PE)-conjugated monoclonal antibodies against CD34 (BD Pharmingen, San Jose, CA, USA) or against vascular endothelial-cadherin (VE-Cadherin, R\&D Systems), or a FITC-conjugated monoclonal antibody against kinase insert domain receptor (KDR, R\&D Systems, Minneapolis, MN, USA), or incubated with monoclonal antibodies against CD31 (Dako, Glostrup, Denmark) and the von Willebrand factor (vWF, Dako) followed by incubation with a secondary antibody conjugated with Cy3 (Chemicon, Temecula, CA). Cells to be stained with vWF were permeabilized with $90 \%$ cold methanol at $-20^{\circ} \mathrm{C}$ for 20 min before incubation with the primary antibody. The immunofluorescence-labeled cells were washed with FACS buffer $(0.5 \%$ BSA and $0.09 \%$ sodium azide in PBS, $\mathrm{pH}$ 7.4) and analyzed by quantitative flow cytometry using FACSCalibur (BD Biosciences, San Jose, CA, USA). The CellQuest software was used for counting 10,000 events/sample. Isotype-identical directly or indirectly conjugated antibodies served as negative controls $\left(\mathrm{IgG}_{1}-\mathrm{FITC}\right.$ for $\mathrm{KDR}$, IgG $\mathrm{IgE}_{1}$-Por CD34, $\mathrm{IgG}_{2 \mathrm{~B}}-\mathrm{PE}$ for VE-Cadherin, and $\mathrm{IgG}_{1}$ for $\mathrm{CD} 31$ and vWF).

Modified Boyden chamber migration assay. Chemotactic migration was evaluated using a modified Boyden chamber as previously described (20). After incubation in serum-free medium for $4 \mathrm{~h}$, day 6 EPCs cultured with fasudil $(1 \sim 10 \mu \mathrm{M})$ or simvastatin $(0.01 \mu \mathrm{M})$ were detached and placed into the upper chamber $\left(2 \times 10^{4}\right.$ cells/well). The low chamber was filled with buffer containing $0.1 \% \mathrm{BSA}, 90 \mu \mathrm{g} / \mathrm{ml}$ heparin, and SDF-1 or VEGF (10 ng/ml) in M199 medium. The assembled chamber was incubated for $6 \mathrm{~h}$ at $37^{\circ} \mathrm{C}$ with $5 \% \mathrm{CO}_{2}$ to allow cells to migrate through the filter. The membrane was removed from the chamber, and stained with Diff-Quik solution (Sysmex, Japan). Non-migrated cells of the upper surface of the membrane were removed. The number of migrated cells was counted in random four fields (x200) of each well. Each experiment was performed in triplicate.

Cell adhesion assay. HUVECs were seeded in 48-well plates by adding $5 \times 10^{4}$ cells/well $24 \mathrm{~h}$ before the assay. Confluent HUVEC monolayers were stimulated for $12 \mathrm{~h}$ with endothelial growth medium-2 SingleQuots (EGM-2 SingleQuots) (Cambrex, Walkersville, MD). EPCs cultured in the presence or absence of fasudil $(10 \mu \mathrm{M})$ for 6 days were labeled with PKH26 (Sigma) according to the manufacturer's instruction. PKH26-labeled EPCs (1x10 $/$ well) were then added to the HUVEC monolayer. After $3 \mathrm{~h}$ of incubation at $37^{\circ} \mathrm{C}$, the cells were washed twice with PBS to remove non-adherent cells, fixed with $4 \%$ paraformaldehyde, and stained with DAPI. The PKH26-labeled EPCs adhering to HUVEC layer were quantified in triplicates.

Tube formation assay. Day 7 EPCs were detached with $1 \mathrm{mM}$ EDTA and labeled with PKH26 (Sigma) according to the manufacturer's instructions. PKH26-labeled EPCs (7,500 cells) were mixed with HUVECs $\left(3 \times 10^{4}\right.$ cells), then seeded onto Matrigel-coated 48 -well plates and incubated at $37^{\circ} \mathrm{C}$ with $5 \%$ $\mathrm{CO}_{2}$ for $22 \mathrm{~h}$. Tube formation was visualized using a phasecontrast microscope, and then the image was overlaid with fluorescence microscopic images (Carl Zeiss).

Transplantation in a hindlimb ischemia murine model. All procedures complied with the Guide for the Care and Use of Laboratory Animals published by the US National Institute of Health (NIH publication no. 85-23, revised 1996). The study 


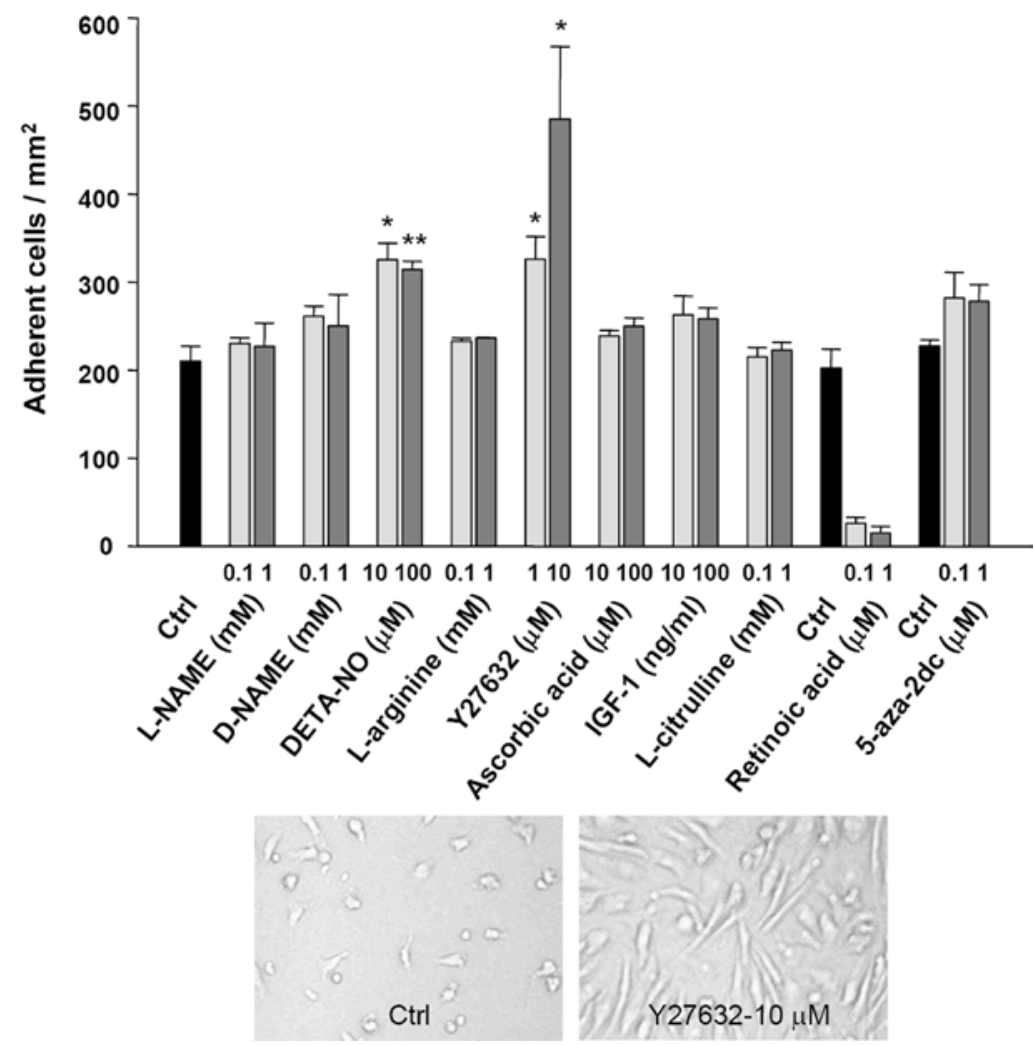

Figure 1. Y27632 markedly increases the number of adherent EPCs. MNCs were seeded on the FN-coated plates at a density of 2,500 cells $/ \mathrm{mm}^{2}$ and incubated in the presence of each chemical for 7 days. The number of adherent cells was counted. Each value represents the mean $\pm \mathrm{SE}$. ${ }^{*} \mathrm{P}<0.05 ;{ }^{* * *} \mathrm{P}<0.01$ compared with each relevant solvent control (Ctrl).

protocol was approved by our Institutional Animal Care and Use Committee.

Male Balb/c Slc-nu mice (Japan SLC, Inc., Japan), 8-weeks of age were anesthetized with an i.p. injection of $100 \mathrm{mg} / \mathrm{kg}$ ketamine hydrochloride and $5 \mathrm{mg} / \mathrm{kg}$ xylazine. Hindlimb ischemia was induced by operative resection of one femoral artery and boundary vessels. No later than $6 \mathrm{~h}$ after operation, one group of mice was transplanted with day 5-6 EPCs $\left(10^{6}\right.$ cells/mouse) cultured in the presence or absence of fasudil $(10 \mu \mathrm{M})$ administered intramuscularly in the ischemic thigh area. Three weeks after surgery, the mice were sacrificed by $\mathrm{CO}_{2}$ inhalation. The sections $(5 \mu \mathrm{m})$ of the tissues that were harvested from ischemic limbs, were stained with fluorescein Griffonia (Bandeiraea) simplicifolia (BS) lectin I (Vector Laboratories, Burlingame, CA), as follows: $5 \mu \mathrm{m}$ muscle tissues were fixed with $100 \%$ acetone for $5 \mathrm{~min}$, washed with PBS twice, blocked with 5\% normal goat serum (Vector Laboratories) for $30 \mathrm{~min}$, and incubated with $20 \mu \mathrm{g} / \mathrm{ml}$ fluorescein BS lectin $\mathrm{I}$ for $1 \mathrm{~h}$ at room temperature. To quantify the vessel density, ImageJ software was used (http://rsbweb.nih.gov/ij/). First, the captured color images were applied to the RGB stack to split the images into each channel. After segmenting each individual image using thresholding (CTRL-EPC group, mice $(n=5), 10$ sections/mouse, 5 fields/section, total 50 images calculated; fasudil-EPC group, mice $(n=5), 10$ sections/mouse, 5 fields/section, total 49 images calculated), the percentages of the vessel area/fields were calculated by ImageJ.

Laser Doppler perfusion imaging of the hindlimb blood flow. Laser Doppler perfusion imaging (LDPI; Perimed PeriScan
PIM3, Stockholm, Sweden) was used to measure the ratio of the ischemic (left)/non-ischemic (right) limb blood flow over the course of 3 weeks postoperatively. After scanning over the same region of interest in each mouse twice, images were subjected to quantification of the blood flow and the averages of the blood flow of the ischemic and non-ischemic limbs were calculated.

Statistical analysis. All values are presented as the means $\pm \mathrm{SE}$ from at least three independent experiments. Statistical analysis was performed using the Student's t-test. Probability values $<0.05$ were considered to be statistically significant.

\section{Results}

ROCK inhibitors increase the number of EPCs. In order to find a way of increasing EPC number and improving their functions by avoiding cellular senescence, we screened several chemicals in in vitro EPC culture by $\beta$-gal senescence assay. Most of the chemicals tested apparently affected EPC senescence during 7 day culture (data not shown). Interestingly, Y27632, a ROCK inhibitor, gave rise to marked increased adherent cells when MNCs isolated from cord blood were cultured on FN-coated dishes for 7 days in the presence of each chemical (Fig. 1). NO donor also slightly increased EPC number. NO has been shown to increase neovascularization in vivo, and various agents that promote eNOS-dependent NO production have been shown to induce therapeutic angiogenesis (21). However, retinoic acid strongly inhibited adhesive differentiation of EPCs. 
A

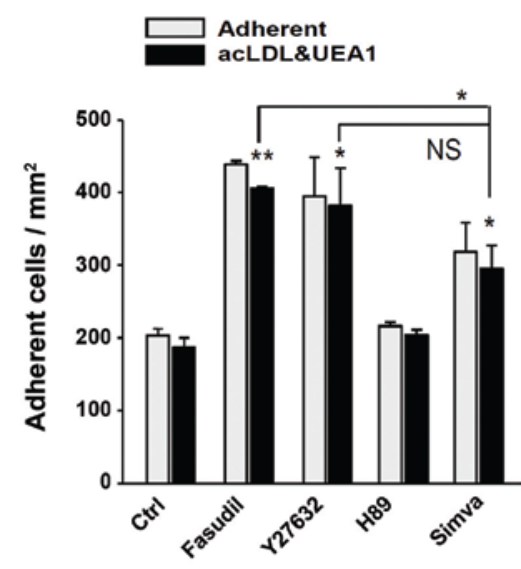

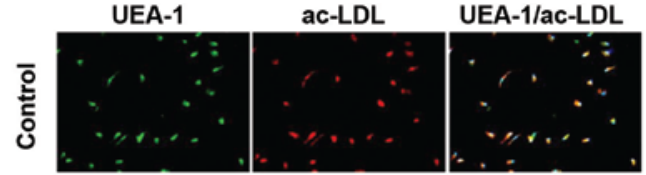

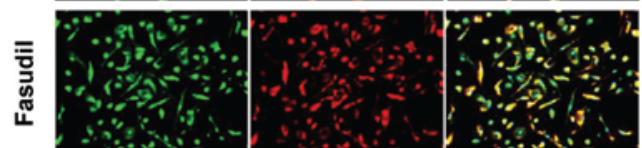

స్్
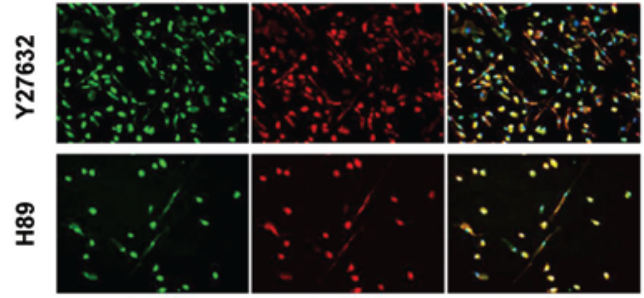

ह

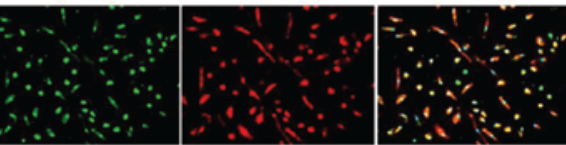

B
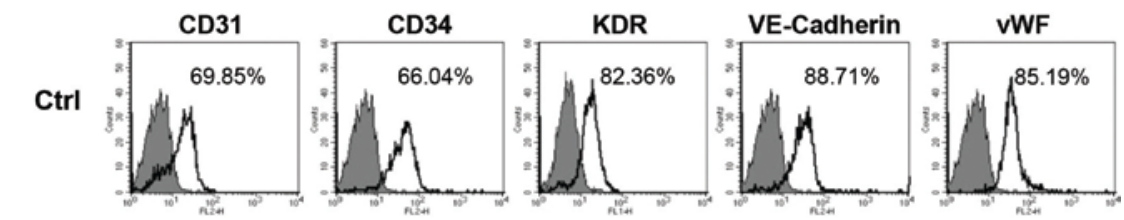

Fasudi
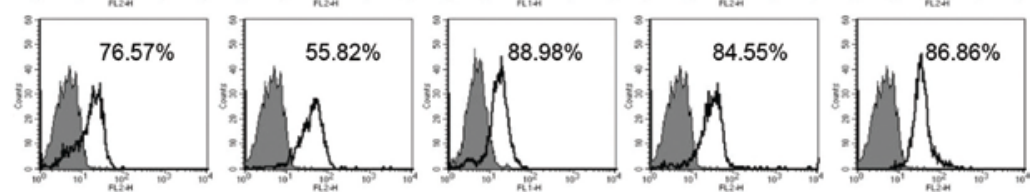

Figure 2. Rho kinase inhibitors with a higher selectivity increase the number of EPCs with greater efficiency. (A) MNCs were incubated in the presence of fasudil, Y27632, H89 $(10 \mu \mathrm{M})$ or simvastatin (Simva, $1 \mu \mathrm{M})$ for 7 days and then adherent EPCs were assessed for the uptake of acLDL (red) and binding of UEA-1 (green). The number of adherent EPCs and acLDL/UEA-1 double positive cells was counted. Each value represents the mean \pm SE. NS, not significant; ${ }^{*} \mathrm{P}<0.05 ;{ }^{* *} \mathrm{P}<0.01$ compared with acLDL/UEA1 positive control cells. Representative photographs are shown. (B) Day 6 EPCs cultured in the presence or absence of fasudil $(10 \mu \mathrm{M})$ were immunolabeled and analyzed for expression of endothelial markers by FACS analysis.
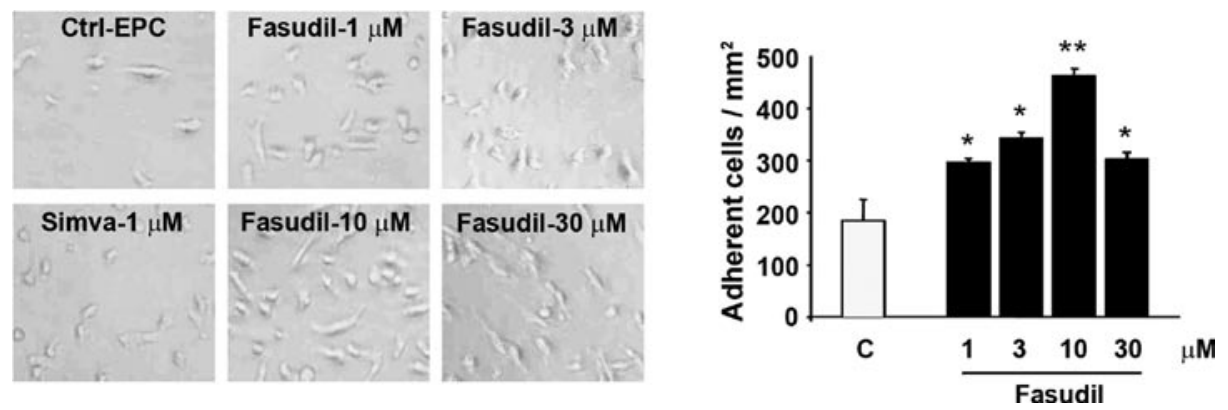

Figure 3. Fasudil dose-dependently increases EPC number. MNCs were incubated in the presence of fasudil in a concentration range of 1-30 $\mu \mathrm{M}$ for 7 days and the number of adherent EPCs was measured. Each value represents the mean \pm SE. NS, not significant; ${ }^{*} \mathrm{P}<0.05 ;{ }^{* * *} \mathrm{P}<0.01$ compared with PBS-treated control cells.

Next, we compared several inhibitors with different levels of selectivity for ROCK and other kinases in EPC culture. Y27632 and fasudil that are the most selective ROCK inhibitors, increased the number of EPCs by 2 -fold compared to PBS-treated controls, whereas a less selective ROCK inhibitor H89, which strongly inhibits protein kinase A, S6 kinase 1 and the mitogen- and stress-activated protein kinase 1 as well as ROCK, had no effect on increasing the number of EPCs (Fig. 2A). A higher number of spindle-shaped cells was observed in fasudil-cultured cells compared to statin- or PBS-treated cells. Most of the adherent cells were double positive for ac-LDL uptake and UEA-1 binding, without a change in the ratio upon treatment with the inhibitor. The enhancing effect of fasudil was distinctly higher than that of simvastatin $(\mathrm{P}<0.05)$. When the expression levels of other endothelial cell markers, CD31, CD34, KDR, VE-Cadherin and vWF, were compared by FACS analysis of immunolabeled cells after culture for 6 days, there were no noticeable differences 


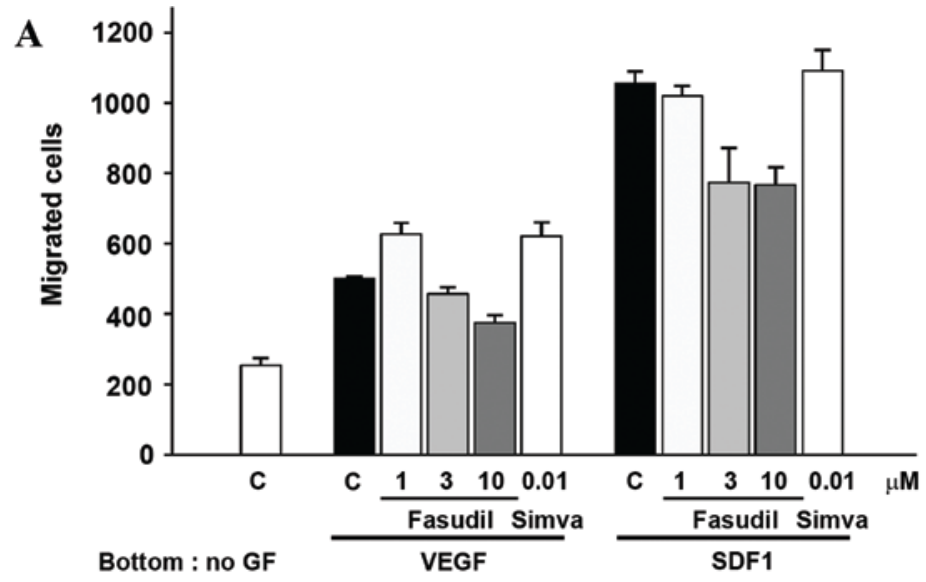

B

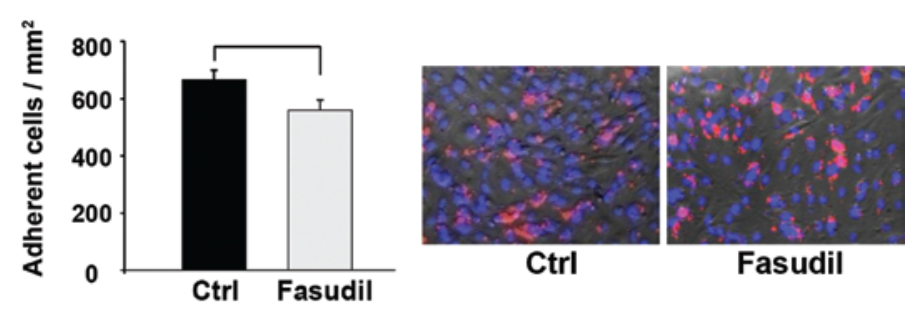

C
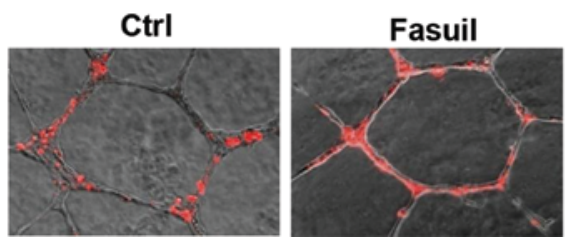

Figure 4. Fasudil-expanded EPCs retain most of the functional properties of non-treated EPCs. (A) MNCs were cultured in the presence or absence of fasudil $(1 \sim 10 \mu \mathrm{M})$ or simvastatin (Simva; $0.01 \mu \mathrm{M})$ for 6 days. These cells were induced to migrate toward VEGF or SDF-1 (10 ng/ml) in a modified Boyden chamber. The number of migrated cells was determined. (B) Day 6 EPCs cultured in the presence of fasudil (10 $\mu \mathrm{M})$ were labeled with PKH26 (red) and then the labeled EPCs ( $10^{5}$ cells/48-well plates) were added onto a confluent HUVEC monolayer, followed by incubation for 3 h. After washing with PBS, the cells were photographed in five fields/each well and the number of the labeled cells adhering to HUVEC layer was counted. Each value represents the mean \pm SE. ${ }^{*} \mathrm{P}<0.05$ vs. control. Representative fields are shown (x200). (C) Day 6 EPCs (7,500 cells) cultured in the presence of fasudil (10 $\left.\mu \mathrm{M}\right)$ were labeled with PKH26 (red), mixed with HUVECs ( $3 \times 10^{4}$ cells), and then incubated on Matrigel for $22 \mathrm{~h}$. Representative fields are shown (x100).

between cells cultured in the presence or absence of fasudil (Fig. 2B).

In order to examine whether the effect of fasudil was dose-dependent, EPCs were treated for 7 days with 1-30 $\mu \mathrm{M}$ fasudil (Fig. 3). Treatment of fasudil increased the number of adherent EPCs dose-dependently up to $10 \mu \mathrm{M}$. However, treatment with the high concentration of $30 \mu \mathrm{M}$ resulted in reduction of the adherent EPCs. From these results, we conclude that ROCK inhibition by fasudil increases the number of EPCs in an ex vivo culture.

Fasudil-expanded EPCs retain the functional properties of EPCs. ROCK inhibitors can either inhibit or enhance cell migration depending on the cell type and conditions (22). Thus, we examined whether EPCs increased upon treatment with fasudil would retain the functional properties of EPCs. When EPCs cultured in the presence of fasudil for 6 days were assayed in a modified Boyden chamber, these cells were able to migrate in response to SDF-1 or VEGF albeit at lower levels compared to non-fasudil-treated cells (Fig. 4A). Even after culture with $10 \mu \mathrm{M}$ of fasudil, EPC migration was much higher than at the non-stimulated basal level $(\mathrm{P}<0.05)$. Next, we assessed whether fasudil-cultured EPCs have a capacity to bind to activated endothelial cells. In an adhesion assay, fasudilcultured EPCs were able to adhere to the HUVEC monolayer at $83.87 \pm 5.36 \%$ of control EPC level (Fig. 4B). Finally, we examined whether fasudil-cultured EPCs retain the ability to incorporate into endothelial tubes. When EPCs cultured in the presence of fasudil was co-incubated with HUVECs on Matrigel, fasudil-cultured EPCs labeled with PKH26 were able to incorporate into tubes formed by HUVECs at a similar level to non-treated control EPCs (Fig. 4C). Thus, these results indicate that fasudil-cultured EPCs retain most of their functional properties. Thus, it could be expected that fasudil-cultured EPCs may function normally without any significant inhibition in vivo.

Fasudil-cultured EPCs show in vivo efficacy at a level comparable with control EPCs in hindlimb ischemia. Finally, we compared the therapeutic effects of fasudil-cultured EPCs with non-treated EPCs in an in vivo ischemic model, to evaluate the possibility of application of fasudil in cell therapy. Within 
A

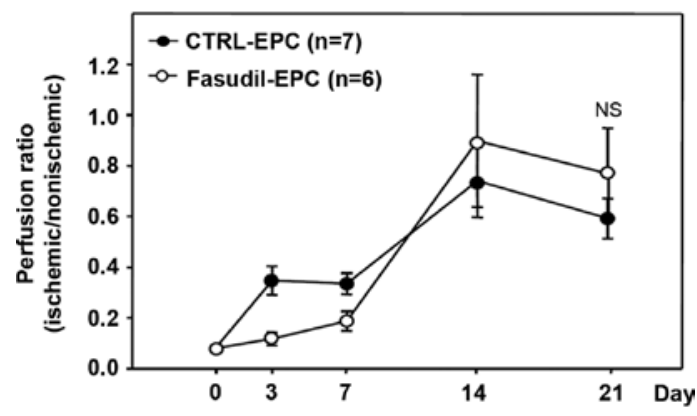

B

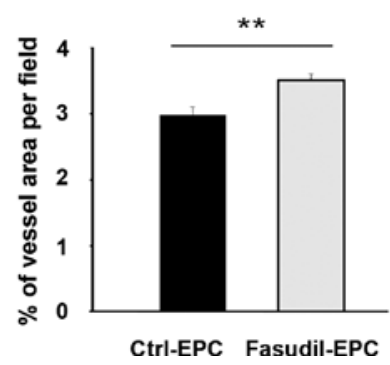

Figure 5. Comparison of blood flow recovery in hindlimb ischemia between fasudil-expanded EPCs and control EPCs. (A) EPCs were cultured with or without fasudil for 5-6 days. EPCs $\left(1 \times 10^{6}\right)$ were intramuscularly injected into the ischemic muscle area. Perfusion was quantified by LDPI as described in Materials and methods. (B) The sections of tissues harvested from ischemic limbs after 3 weeks were stained with fluorescein BS lectin I and the vessel density was measured as described in Materials and methods. NS, not significant; ${ }^{* *} \mathrm{P}<0.01$.

$6 \mathrm{~h}$ after operation, EPCs cultured with or without fasudil for 5-6 days were locally injected into the ischemic thigh muscle area $\left(10^{6}\right.$ cells) at four different injection points. Serial LDPI analyses showed overall similar levels of recovery of blood flow between control EPCs and fasudil-cultured EPCs, but slightly better recovery was observed in fasudil-cultured EPCs on days 14 and 21 by showing higher mean augmented ratios of the ischemic/non-ischemic limb blood flow in the limbs injected with fasudil-cultured EPCs (Fig. 5A). When tissue sections harvested from the ischemic hindlimb at day 21 after operation were inspected by BS lectin I staining, an increase in vessel density was observed in the fasudil-cultured EPC group compared to the control-EPC group (Fig. 5B). Therefore, the results suggest that fasudil-cultured EPCs are effective in therapeutic vascularization in vivo.

\section{Discussion}

The data from the present study establish a novel effect of ROCK inhibitors in EPCs in ex vivo culture. Fasudil increased EPC number and fasudil-expanded EPCs retained most of the functional characteristics of control EPCs. Therefore, this study suggests that fasudil may be used for ex vivo expansion of EPCs for cell therapy.

Y27632 and fasudil are relatively more selective for ROCK compared to H89 (23). Accordingly, they showed a better effect on EPCs by enhancing the yields of adherent EPCs in an ex vivo culture assay. Simvastatin also increased EPC number, in accordance with a previous report (17), but the increased level by simvastatin was lower than that by fasudil treatment. Since gene knockdown experiments in EPCs with small interfering RNA (siRNAs) failed, we cannot conclude that ROCK inhibition results in an increase of EPC number at the molecular level. However, ROCK inhibitors may be beneficial in EPC culture, since only the more selective ROCK inhibitors effectively enhanced the number of EPCs. Another group has reported that fasudil modifies the detrimental effect of TNF- $\alpha$ on human peripheral blood EPCs by recovering EPC number (24), supporting our notion that fasudil positively affects EPC number. However, in a previous study, treatment of fasudil for $24 \mathrm{~h}$ did not noticeably augment EPC number when MNCs from the peripheral blood of healthy human volunteers were treated (16). Therefore, the treatment period of the inhibitor and the prior cell environment, such as the exposed cytokine composition may influence the effect of a ROCK inhibitor on EPC number.

ROCK is involved in the actin-cytoskeleton rearrangement and therefore affects cell motility (22). ROCK inhibitors can either inhibit or enhance cell migration depending on the cell type and the conditions. Fasudil-expanded EPCs show a comparable migratory activity and adhesion with non-treated EPCs although with some level of inhibition. In addition, incorporation into HUVEC-derived tubes was not affected by fasudil treatment in EPC culture. Fasudil-expanded EPCs were also comparably effective in therapeutic vascularization and perfusion recovery after ischemia. Thus, the data strongly support that fasudil can be used for EPC expansion.

The clinical beneficial effect of fasudil on ischemic diseases, such as stroke has been described. However, the mechanisms underlying the fasudil effect are not fully understood. Amelioration of endothelial damage/dysfunction has been suggested as a possible mechanism for the neuroprotective effects of ROCK inhibitors against ischemic brain damage (25). Leukocyte ROCK activity is increased after ischemic stroke (26), and anti-inflammation through inhibition of leukocytes by fasudil may be another possible mechanism. However, a population of leukocytes may be the EPCs with the increased ROCK activity. Notably, inhibition of RhoA GTPase activity has been reported to enhance hematopoietic stem and progenitor cell proliferation and engraftment, although with reduced migration and adhesion (27). Thus, it can be suggested that EPCs may be a target of ROCK inhibitors in ischemia. Taken together, these results provide insight for the usefulness of fasudil in ischemic disease.

\section{Acknowledgements}

This study was supported by a grant of the Korea Healthcare Technology R\&D Project, Ministry of Health and Welfare, Republic of Korea (A080517).

\section{References}

1. Kalka C, Masuda H, Takahashi T, Kalka-Moll WM, Silver M, Kearney M, Li T, Isner JM and Asahara T: Transplantation of ex vivo expanded endothelial progenitor cells for therapeutic neovascularization. Proc Natl Acad Sci USA 97: 3422-3427, 2000.

2. Asahara T, Masuda H, Takahashi T, Kalka C, Pastore C, Silver M, Kearne M, Magner M and Isner JM: Bone marrow origin of endothelial progenitor cells responsible for postnatal vasculo-genesis in physiological and pathological neovascularization. Circ Res 85: 221-228, 1999. 
3. Takahashi T, Kalka C, Masuda H, Chen D, Silver M, Kearney M, Magner M, Isner JM and Asahara T: Ischemia- and cytokineinduced mobilization of bone marrow-derived endothelial progenitor cells for neovascularization. Nat Med 5: 434-438, 1999.

4. Asahara T, Takahashi T, Masuda H, Kalka C, Chen D, Iwaguro H, Inai Y, Silver M and Isner JM: VEGF contributes to postnatal neovascularization by mobilizing bone marrow-derived endothelial progenitor cells. EMBO J 18: 3964-3972, 1999.

5. Yamaguchi J, Kusano KF, Masuo O, Kawamoto A, Silver M, Murasawa S, Bosch-Marce M, Masuda H, Losordo DW, Isner JM and Asahara T: Stromal cell-derived factor-1 effects on ex vivo expanded endothelial progenitor cell recruitment for ischemic neovascularization. Circulation 107: 1322-1328, 2003.

6. Loirand G, Guerin P and Pacaud P: Rho kinases in cardiovascular physiology and pathophysiology. Circ Res 98: 322-334, 2006.

7. Takemoto M, Sun J, Hiroki J, Shimokawa H and Liao JK: Rhokinase mediates hypoxia-induced downregulation of endothelial nitric oxide synthase. Circulation 106: 57-62, 2002.

8. Ming XF, Viswambharan H, Barandier C, Ruffieux J, Kaibuchi K, Rusconi S and Yang Z: Rho GTPase/Rho kinase negatively regulates endothelial nitric oxide synthase phosphorylation through the inhibition of protein kinase B/Akt in human endothelial cells. Mol Cell Biol 22: 8467-8477, 2002.

9. Wolfrum S, Dendorfer A, Rikitake Y, Stalker TJ, Gong Y, Scalia R, Dominiak P and Liao JK: Inhibition of Rho-kinase leads to rapid activation of phosphatidylinositol 3-kinase/protein kinase Akt and cardiovascular protection. Arterioscler Thromb Vasc Biol 24: 1842-1847, 2004

10. Nohria A, Grunert ME, Rikitake Y, Noma K, Prsic A, Ganz P, Liao JK and Creager MA: Rho kinase inhibition improves endothelial function in human subjects with coronary artery disease. Circ Res 99: 1426-1432, 2006.

11. Shimokawa $\mathrm{H}$ and Takeshita A: Rho-kinase is an important therapeutic target in cardiovascular medicine. Arterioscler Thromb Vasc Biol 25: 1767-1775, 2005.

12. Liao JK, Seto M and Noma K: Rho kinase (ROCK) inhibitors. J Cardiovasc Pharmacol 50: 17-24, 2007.

13. Dong M, Yan BP, Liao JK, Lam YY, Yip GW and Yu CM: Rhokinase inhibition: a novel therapeutic target for the treatment of cardiovascular diseases. Drug Discov Today 15: 622-629, 2010

14. Liao JK: Does it matter whether or not a lipid-lowering agent inhibits Rho kinase? Curr Atheroscler Rep 9: 384-388, 2007.

15. Liu PY, Liu YW, Lin LJ, Chen JH and Liao JK: Evidence for statin pleiotropy in humans: differential effects of statins and ezetimibe on rho-associated coiled-coil containing protein kinase activity, endothelial function, and inflammation. Circulation 119: 131-138, 2009.
16. Dimmeler S, Aicher A, Vasa M, Mildner-Rihm C, Adler K, Tiemann M, Rütten H, Fichtlscherer S, Martin H and Zeiher AM: HMG-CoA reductase inhibitors (statins) increase endothelial progenitor cells via the PI 3-kinase/Akt pathway. J Clin Invest 108: 391-397, 2001.

17. Llevadot J, Murasawa S, Kureishi Y, Uchida S, Masuda H, Kawamoto A, Walsh K, Isner JM and Asahara T: HMG-CoA reductase inhibitor mobilizes bone marrow-derived endothelial progenitor cells. J Clin Invest 108: 399-405, 2001.

18. Jaffe EA, Nachman RL, Becker CG and Minick CR: Culture of human endothelial cells derived from umbilical veins. Identification by morphologic and immunologic criteria. J Clin Invest 52: 2745-2756, 1973

19. O E, Lee BH, Ahn HY, Shin JC, Kim HK, Kim M, Park IY, Park YG and Joe YA: Efficient non-adhesive ex vivo expansion of early endothelial progenitor cells derived from $\mathrm{CD} 34^{+}$human cord blood fraction for effective therapeutic vascularization. FASEB J 25: 159-169, 2011.

20. Oh HK, Ha JM, O E, Lee BH, Lee SK, Shim BS, Hong YK and Joe YA: Tumor angiogenesis promoted by ex vivo differentiated endothelial progenitor cells is effectively inhibited by an angiogenesis inhibitor, TK1-2. Cancer Res 67: 4851-4859, 2007.

21. Namkoong S and KIM YM: Therapeutic application of nitric oxide in human diseases. Biomol Ther 18: 351-362, 2010.

22. Riento K and Ridley AJ: Rocks: multifunctional kinases in cell behaviour. Nat Rev Mol Cell Biol 4: 446-456, 2003.

23. Davies SP, Reddy H, Caivano M and Cohen P: Specificity and mechanism of action of some commonly used protein kinase inhibitors. Biochem J 351: 95-105, 2000

24. Balestrieri ML, Giovane A, Milone L, Felice F, Fiorito C, Crudele V, Esposito A, Rossiello R, Minucci PB, Farzati B, Servillo L and Napoli C: Modification of the detrimental effect of TNF-alpha on human endothelial progenitor cells by fasudil and Y27632. J Biochem Mol Toxicol 24: 351-360, 2010.

25. Satoh S, Hitomi A, Ikegaki I, Kawasaki K, Nakazono O, Iwasaki M, Mohri M and Asano T: Amelioration of endothelial damage/ dysfunction is a possible mechanism for the neuroprotective effects of Rho-kinase inhibitors against ischemic brain damage. Brain Res Bull 81: 191-195, 2010.

26. Feske SK, Sorond FA, Henderson GV, Seto M, Hitomi A, Kawasaki K, Sasaki Y, Asano T and Liao JK: Increased leukocyte ROCK activity in patients after acute ischemic stroke. Brain Res 1257: 89-93, 2009.

27. Ghiaur G, Lee A, Bailey J, Cancelas JA, Zheng Y and Williams DA: Inhibition of RhoA GTPase activity enhances hematopoietic stem and progenitor cell proliferation and engraftment. Blood 108: 2087-2094, 2006. 